\title{
Paromomycin Loaded Solid Lipid Nanoparticles: Characterization of Production Parameters
}

\author{
Maryam Ghadiri, Alireza Vatanara, Delaram Doroud, Shohreh Fatemi, and Abdolhossein Rouholamini Najafabadi
}

Received: 19 September 2010 / Revised: 21 December 2010 / Accepted: 27 December 2010

(C) The Korean Society for Biotechnology and Bioengineering and Springer 2011

In the 2011 issue of Biotechnology and Bioprocess Engineering (BBE), an error occurred in the research article: Maryam Ghadiri, Alireza Vatanara, Delaram Doroud, Shohreh Fatemi, and Abdolhossein Rouholamini Najafabadi (2011) Paromomycin Loaded Solid Lipid Nanoparticles: Characterization of Production Parameters. Biotechnol. Bioprocess Eng. 16: 617-623.

- In the authors's name

Original wording:

Maryam Ghadiri, Delaram Doroud

Department of Chemical Engineering, Faculty of Engineering, University of Tehran, Tehran, Iran Tel: +98-21-6695-9057; Fax: +98-21-6646-1178

E-mail: shfatemi@ut.ac.ir

Alireza Vatanara, A. Roholamini Najafabadi Department of Pharmaceutics, School of Pharmacy, Tehran University of Medical Sciences, Tehran, Iran
This should be replaced by: Maryam Ghadiri, Shohreh Fatemi*

Department of Chemical Engineering, Faculty of Engineering, University of Tehran, Tehran, Iran Tel: +98-21-6695-9057; Fax: +98-21-6646-1178 E-mail: shfatemi@ut.ac.ir

Delaram Doroud, Alireza Vatanara, Abdolhossein Rouholamini Najafabadi

Department of Pharmaceutics, School of Pharmacy, Tehran University of Medical Sciences, Tehran, Iran

Received: 4 October 2011

Maryam Ghadiri, Delaram Doroud, Shohreh Fatemi*

Department of Chemical Engineering, Faculty of Engineering, University of Tehran, Tehran, Iran

Tel: +98-21-6695-9057; Fax: +98-21-6646-1178

E-mail:shfatemi@ut.ac.ir

Alireza Vatanara, Abdolhossein Rouholamini Najafabadi Department of Pharmaceutics, School of Pharmacy, Tehran University of Medical Sciences, Tehran, Iran 